\title{
Impact of Aerobic Exercise Training on Endothelial Function in Acute Coronary Syndrome
}

\author{
Chul Kim, MD, PhD ${ }^{1}$, Hee Eun Choi, $\mathrm{MD}^{2}$, Heejin Jung, $\mathrm{MD}^{1}$, Seong Hoon Kang, $\mathrm{MD}^{1}$, \\ Jeong Hoon Kim, $\mathrm{MD}^{3}$, Young Sup Byun, $\mathrm{MD}^{3}$ \\ ${ }^{1}$ Department of Rehabilitation Medicine, Inje University Sanggye Paik Hospital, Seoul; \\ ${ }^{2}$ Department of Rehabilitation Medicine, Inje University Haeundae Paik Hospital, Busan; \\ ${ }^{3}$ Division of Cardiology, Departments of Internal Medicine, Inje University Sanggye Paik Hospital, Seoul, Korea
}

\begin{abstract}
Objective To confirm the improvement in arterial endothelial function by aerobic exercise training, flowmediated dilation (FMD) was tested by ultrasonography.

Methods Patients who received percutaneous coronary intervention due to acute coronary syndrome were included. The patients who participated in cardiac rehabilitation (CR) program were categorized as the CR group, and others who did not participate as the control. Both groups underwent initial graded exercise test (GXT) and FMD testing. Subsequently, the CR group performed aerobic exercise training sessions. Patients in control only received advice regarding the exercise methods. After six weeks, both groups received follow-up GXT and FMD testing.

Results There were 16 patients in each group. There were no significant differences in the general characteristics between the groups. The $\mathrm{VO}_{2 \text { peak }}$ was $28.6 \pm 4.7 \mathrm{~mL} / \mathrm{kg} / \mathrm{min}$ in the CR group and $31.5 \pm 7.4 \mathrm{~mL} / \mathrm{kg} / \mathrm{min}$ in the control at first GXT, and was $31.1 \pm 5.1 \mathrm{ml} / \mathrm{kg} / \mathrm{min}$ in the CR group and $31.4 \pm 6.0 \mathrm{ml} / \mathrm{kg} / \mathrm{min}$ in the control at the followup GXT in six weeks. There was a statistically significant improvement in $\mathrm{VO}_{2 \text { peak }}$ only for CR group patients. FMD value was $7.59 \% \pm 1.26 \%$ in the CR group, $7.36 \% \pm 1.48 \%$ in the control at first and $9.46 \% \pm 1.82 \%$ in the CR group, and $8.31 \% \pm 2.04 \%$ in the control after six weeks. There was a statistically significant improvement in FMD value in the CR group.

Conclusion According to the results of GXT and FMD testing, six-week exercise-based CR program improved $\mathrm{VO}_{2 \text { peak }}$ and endothelial functions significantly. Thus, exercise-based CR program is necessary in patients with coronary artery disease.
\end{abstract}

Keywords Acute coronary syndrome, Exercise, Rehabilitation, Endothelial cell, Flow-mediated dilation

Received November 7, 2013; Accepted December 30, 2013

Corresponding author: Heejin Jung

Department of Rehabilitation Medicine, Inje University Sanggye Paik Hospital, 1342 Dongil-ro, Nowon-gu, Seoul 139-707, Korea

Tel: +82-2-950-1134, Fax: +82-2-935-3076, E-mail: s3034@paik.ac.kr

(a) This is an open-access article distributed under the terms of the Creative Commons Attribution Non-Commercial License (http://creativecommons. org/licenses/by-nc/3.0) which permits unrestricted noncommercial use, distribution, and reproduction in any medium, provided the original work is properly cited.

Copyright $\odot 2014$ by Korean Academy of Rehabilitation Medicine

\section{INTRODUCTION}

Endothelium maintains the homeostasis of blood vessel by secreting various bioactive factors, and nitric oxide (NO) is one of the most important endothelium-derived factors [1-3]. NO not only functions as an endotheliumderived dilatation factor but also suppresses monocyte, leukocyte, and platelet adhesion. It also has anti-ath- 
erogenic property, anti-oxidative property, and smooth muscle cell proliferation suppressing property [4]. Endothelial dysfunction results from the failure of vascular homeostasis, and one of the main causes is the failure in the formation or activity of NO [5,6]. Many studies have made it clear that endothelial dysfunction is related to the development of atherosclerotic cardiovascular diseases. It is also known as an early marker of atherosclerosis as atherosclerotic plaques can be checked faster than in radiological examination, such as angiography or ultrasonic examination $[7,8]$. According to the study by Hambrecht et al. [9], the aerobic exercise enhances endothelial function, and coronary circulation can be verified by angiography. Seen from these studies, aerobic exercise can improve endothelium dysfunction and retard the progress or its severity of atherosclerosis $[3,10,11]$. There are various methods to evaluate endothelial function but methods, such as coronary catheterization and venous occlusion plethysmography, are relatively considered as an invasive method. Therefore, application to all cardiovascular disease patients is difficult. Also the high cost for repetitive examinations to verify the improvement of endothelial function acts as a disadvantage. The noninvasive flow-mediated dilation (FMD) of brachial artery diameter with high-resolution sonography is commonly used. However, there have only been few objective reports on non-invasive methods of endothelial function evaluation after aerobic exercise in patients with acute coronary syndrome.

As endothelial dysfunction of peripheral blood vessel is closely related to endothelial dysfunction of coronary artery and reflects general aspects of atherosclerosis, the evaluation of cardiovascular endothelial function and therapeutic effect is possible by non-invasive FMD in peripheral arteries [12].

The purpose of this study is to see if aerobic exercise can improve endothelial function as measured by FMD test, observe changes in exercise capacity through exercise test, and examine the relationship between exercise capacity improvement and endothelial function improvement.

\section{MATERIALS AND METHODS}

\section{Subjects}

The subjects for this study were patients younger than
70 years of age who were hospitalized at Cardiovascular Center of Inje University Sanggye Paik Hospital from April 2011 to July 2012 due to acute coronary syndrome and underwent successful percutaneous coronary intervention (PCI), and were then referred to cardiac rehabilitation (CR) clinic. Patients with previous history of cardiac diseases-such as heart failure or valvular disease, cardiovascular disease, ejection fraction of left ventricle lower than $40 \%$ on echocardiography, deterioration or paralysis due to cerebrovascular disease or musculoskeletal disease, limb defect-and suffering from pain due to musculoskeletal disease were excluded from this study. Those who were educated on the requirements of CR and the contents of the program and participated in the hospital's CR program for aerobic exercise were classified as the CR group, while those who continuously visited the hospital and whose progress was observed without participating in the hospital's CR program were classified as the control. According to the questionnaire survey, control group did not exercise more than just taking a walk, and patients who regularly exercised were excluded from the study. We retrospectively reviewed the medical records of 32 patients. The study was further reviewed and approved by the Institutional Review Board.

\section{Methods}

Prior to the exercise program, patients in the CR group visited the $\mathrm{CR}$ clinic to be evaluated with graded exercise test (GXT) and other preliminary tests including the FMD test. After a six-week exercise program, GXT and FMD tests were repeated. Those in the control group also visited the CR clinic for baseline GXT and other preliminary tests including the FMD test. These patients were educated on risk factor management and self-exercise, and were encouraged to reduce these risk factors and exercise on their own. GXT and FMD test were also repeated after six weeks for this group.

\section{Flow-mediated dilation test}

Numerous factors affect flow-mediated vascular reactivity, including food, drug, and sympathetic stimuli. Therefore, patients stopped taking medication, such as antihypertensive drugs and vasodilator, etc., for three days prior to the FMD test and stopped taking foods and drinks containing caffeine for 48 hours prior to the test. After a 5-minute resting period in supine posture, the 
right upper extremity was examined with iE33 ultrasound scanner (Philips Healthcare, Andover, MA, USA) with an $11 \mathrm{MHz}$ linear transducer (Fig. 1). After longitudinally reviewing the right brachial artery $2-3 \mathrm{~cm}$ above the antecubital fossa, the diameter of right brachial artery was measured in the end-diastolic phase. At the upper part of right forearm, a distal part of the target artery, pneumatic tourniquet was located and a pressure of 200 or 50 mmHg higher than the systolic pressure was applied for 5 minutes. When the cuff is released, blood flow increases along with shear stress, which then expands the blood vessel. Using this principle, the diameter of brachial artery was measured at 45,60 , and 120 seconds after the

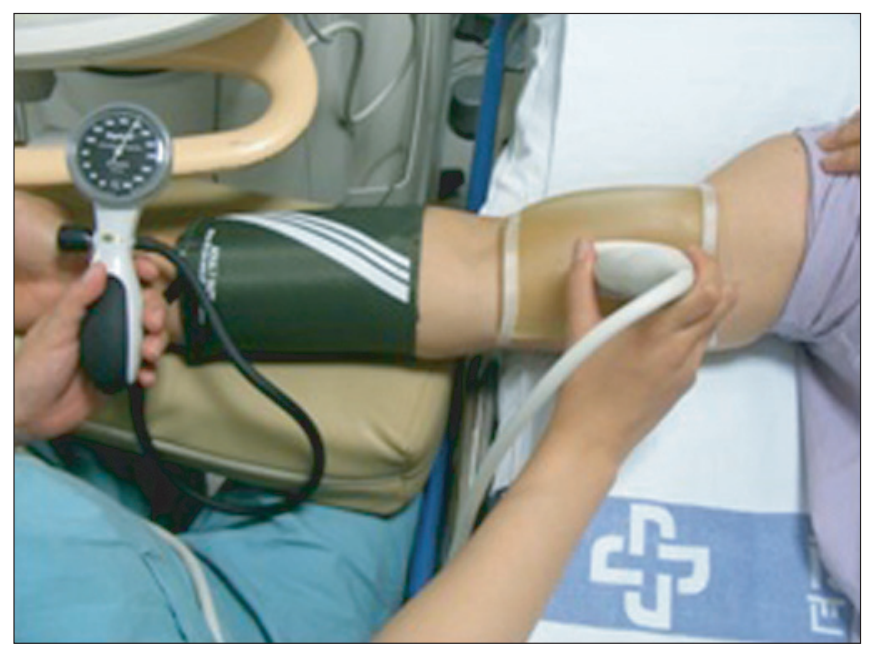

Fig. 1. Flow-mediated dilation testing in the right brachial artery longitudinally $2-3 \mathrm{~cm}$ above the antecubital fossa, by means of iE33 ultrasound scanner (Philips) with the linear transducer $11 \mathrm{MHz}$. release of the cuff, and the maximum value of the three was used for analysis. The baseline and maximum diameter of brachial artery were determined, and FMD (\%) was calculated with the following formula: (maximum diameter during reactive hyperemia - diameter at baseline) / diameter at baseline $\times 100$ [13]. FMD tests were performed by a single experienced sonographer who was blinded to group assignment of each subject (Fig. 2).

\section{Graded exercise test}

GXT was performed according to the symptom limited method of modified Bruce protocol by the recommendation of the American Association of Cardiovascular and Pulmonary Rehabilitation. During exercise, patients were observed in terms of electrocardiogram (ECG) change, heart rate, and blood pressure as objective monitoring indicators and Borg rating of perceived exertion as subjective indicators.

\section{Cardiac rehabilitation program}

After obtaining the maximum heart rate and resting heart rate from GXT, heart rate reserve was calculated, and $40 \%-85 \%$ of the heart rate reserve was determined as the target heart rate. During exercise training, patients were observed in terms of ECG change, heart rate, and blood pressure as objective monitoring indicators while Borg rating of perceived exertion as subjective indicators. Each exercise consisted of 10-minute warm-up, 30-minute main exercise, and 10-minute cool-down exercise. The main exercise consisted of 8 minutes of treadmill, 3 minutes of rest, 8 minutes of bicycle ergometer, 3 minutes of rest, and 8 minutes of treadmill, respectively. Patients
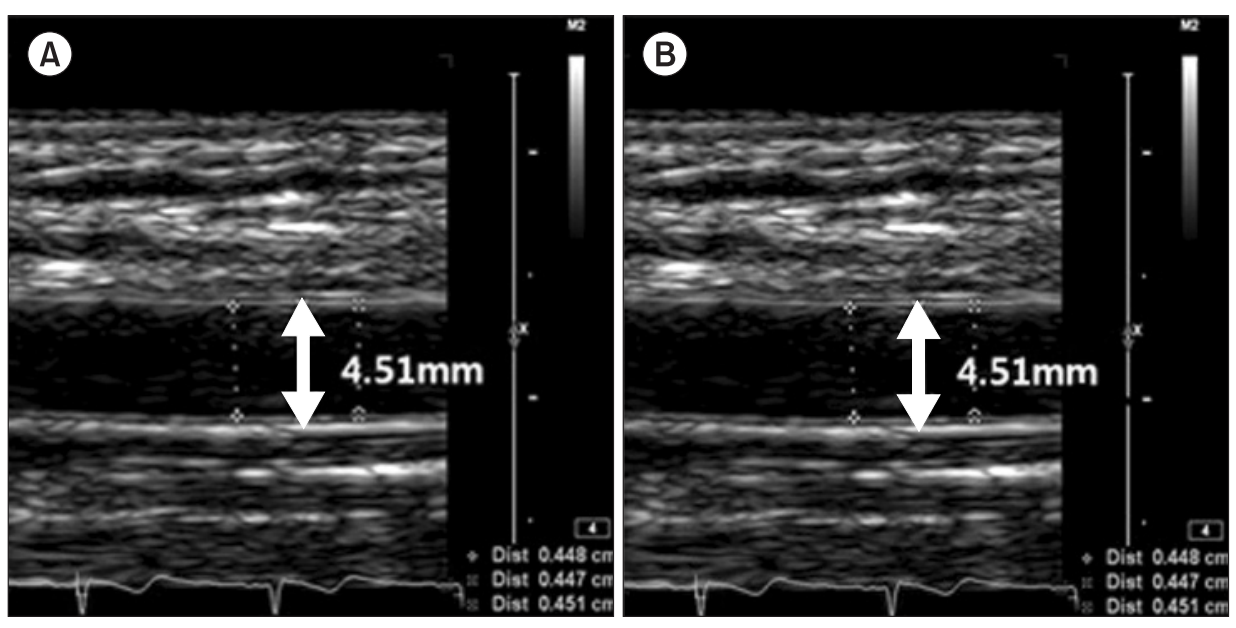

Fig. 2. Flow-mediated dilation was calculated as an increase of vascular diameter from the difference between maximum and baseline brachial artery diameter. The diameter of brachial artery was measured 45, 60, and 120 seconds after cuff release, and the maximum value of the three was used for analysis. (A) Baseline, (B) reactive hyperemia. 
participated in such 50-minute exercise programs three times a week for six weeks (18 exercises in total). To control risk factors of coronary artery disease, all the patients were educated on diet, nutrition, and smoking cessation,

Table 1. Demographic data of study subjects

\begin{tabular}{lccc}
\hline \multicolumn{1}{c}{ Variable } & $\begin{array}{c}\text { Control } \\
\text { (n=16) }\end{array}$ & $\begin{array}{c}\text { CR group } \\
(\mathbf{n = 1 6 )}\end{array}$ & p-value \\
\hline Sex (male:female) & $15: 1$ & $14: 2$ & 0.333 \\
Age (yr) & $52.9 \pm 8.5$ & $54.8 \pm 9.5$ & 0.549 \\
Clinical diagnosis (\%) & & & \\
\hline UA & 37.5 & 62.5 & 0.083 \\
\hline NSTEMI & 18.8 & 12.5 & 0.333 \\
\hline STEMI & 43.8 & 25.0 & 0.164 \\
Hypertension (\%) & 43.8 & 56.3 & 0.164 \\
Diabetes (\%) & 31.3 & 12.5 & 0.083 \\
History of smoking (\%) & & & \\
Never & 25.0 & 25.0 & - \\
\hline Smoker & 62.5 & 37.5 & 0.100 \\
\hline Ex-smoker & 12.5 & 37.5 & 0.100 \\
PCI to 1st FMD (day) & $25.4 \pm 8.3$ & $25.3 \pm 6.3$ & 0.962 \\
Stent inserted vessel (\%) & & & \\
\hline LAD & 37.5 & 37.5 & - \\
\hline RCA & 37.5 & 43.8 & 0.333 \\
\hline LCX & 18.8 & 18.8 & - \\
\hline Others & 6.3 & 0.0 & 0.333 \\
Current medications (\%) & & & \\
\hline ACEi & 37.5 & 43.8 & 0.333 \\
\hline ARB & 12.5 & 0.0 & 0.164 \\
\hline ARB+CCB & 0.0 & 6.3 & 0.333 \\
\hline Beta blocker & 62.5 & 43.8 & 0.083 \\
\hline CCB & 6.3 & 6.3 & - \\
\hline Statins & 100.0 & 100.0 & - \\
\hline Diuretics & 6.3 & 0.0 & 0.333 \\
\hline Nitrates & 43.8 & 56.3 & 0.164 \\
\hline Aspirin & 100.0 & 100.0 & - \\
\hline Clopidogrel & 93.8 & 100.0 & 0.333 \\
\hline Valus are presented as & & & \\
\hline
\end{tabular}

Values are presented as means and occasionally mean \pm standard deviation.

CR, cardiac rehabilitation; UA, unstable angina; NSTEMI, non-ST elevation myocardial infarction; STEMI, ST elevation myocardial infarction; PCI, percutaneous coronary intervention; FMD, flow-mediated dilation; LAD, left anterior descending coronary artery; RCA, right coronary artery; LCX, left circumflex coronary artery; ACEi, angiotensin converting enzyme inhibitor; $\mathrm{ARB}$, angiotensin receptor blocker; CCB, calcium channel blocker. and were prescribed cardiovascular medications for hypertension, diabetes, and dyslipidemia. Afterwards, risk factors of coronary artery disease were evaluated, educated, and continuously strictly controlled through the six weeks.

\section{Statistical analysis}

All statistical analyses were performed using SPSS ver. 18 (SPSS Inc., Chicago, IL, USA). Mann-Whitney U test was used for continuous variables, and Pearson chisquare test for comparing nominal variables between the CR group and the control, such as sex, age, name of diseases, smoking status, the location of stent insertion, time from PCI to FMD, medications taken, cardiovascular risk factor information, initial $\mathrm{VO}_{2 \text { peak }}$, and $\mathrm{FMD}$ value. Changes in $\mathrm{VO}_{2 \text { peak }}$ and $\mathrm{FMD}$ between each group after the six-week exercise program were compared using Wilcoxon signed rank-sum test. To see the correlation between initial FMD and FMD change rate, bivariate correlation test was made using Spearman correlation coefficient. The p-values less than 0.05 were considered to be statistically significant.

\section{RESULTS}

\section{General characteristics}

A total of 32 patients were included in the study with 16 patients divided into each group. In the CR group, there were 15 men and 1 woman, while there were 14 men and 2 women in the control ( $p>0.05)$. The average age of the CR group was 52.9 years, while the average age of the control was 54.8 years $(p>0.05)$. Both groups took FMD tests and GXT after an average of 25 days from PCI. The patterns of acute coronary syndrome were classified as unstable angina, ST elevation myocardial infarction, and non-ST elevation myocardial infarction. There existed no significant intergroup differences in the number and location of blood vessels where the stents were placed. There were also no baseline differences in terms of left ventricle ejection fraction, risk factors (hypertension, diabetes, dyslipidemia, smoking history, and body mass index), and medications taken between the groups (Tables $1,2)$.

\section{Comparison of $\mathrm{VO}_{2 \text { peak }}$ in both groups}

The baseline $\mathrm{VO}_{2 \text { peak }}$ from the initial GXT was $28.6 \pm 4.7$ $\mathrm{mL} / \mathrm{kg} / \mathrm{min}$ in the CR group and $31.5 \pm 7.4 \mathrm{~mL} / \mathrm{kg} / \mathrm{min}$ 
Table 2. Baseline clinical parameters between groups

\begin{tabular}{|c|c|c|c|}
\hline Parameter & Control $(n=16)$ & CR group $(n=16)$ & p-value \\
\hline $\operatorname{BMI}\left(\mathrm{kg} / \mathrm{m}^{2}\right)$ & $25.7 \pm 2.0$ & $25.5 \pm 3.6$ & 0.847 \\
\hline $\mathrm{HR}_{\text {rest }}$ (beats/min) & $69 \pm 14$ & $70 \pm 12$ & 0.924 \\
\hline $\mathrm{SBP}_{\text {rest }}(\mathrm{mmHg})$ & $108 \pm 10$ & $113 \pm 7$ & 0.108 \\
\hline $\mathrm{DBP}_{\text {rest }}(\mathrm{mmHg})$ & $78 \pm 7$ & $76 \pm 10$ & 0.673 \\
\hline $\mathrm{HR}_{\text {peak }}$ (beats/min) & $146.44 \pm 19.20$ & $146.81 \pm 20.88$ & 0.926 \\
\hline $\mathrm{SBP}_{\text {peak }}(\mathrm{mmHg})$ & $166.62 \pm 32.44$ & $176.75 \pm 26.27$ & 0.341 \\
\hline $\mathrm{DBP}_{\text {peak }}(\mathrm{mmHg})$ & $76.25 \pm 10.36$ & $73.13 \pm 13.51$ & 0.616 \\
\hline RER & $1.10 \pm 0.11$ & $1.12 \pm 0.07$ & 0.724 \\
\hline Exercise duration (min) & $15.77 \pm 2.06$ & $16.52 \pm 5.30$ & 0.381 \\
\hline Cholesterol (mg/dL) & $184.8 \pm 27.1$ & $175.5 \pm 34.7$ & 0.411 \\
\hline $\mathrm{LDL}(\mathrm{mg} / \mathrm{dL})$ & $124.4 \pm 20.7$ & $112.1 \pm 28.1$ & 0.171 \\
\hline $\mathrm{HDL}(\mathrm{mg} / \mathrm{dL})$ & $42.8 \pm 6.7$ & $46.6 \pm 10.7$ & 0.246 \\
\hline $\mathrm{TG}(\mathrm{mg} / \mathrm{dL})$ & $135.6 \pm 73.8$ & $142.1 \pm 63.8$ & 0.793 \\
\hline hs-CRP (mg/dL) & $1.45 \pm 3.47$ & $1.11 \pm 2.53$ & 0.692 \\
\hline $\operatorname{HbAlC}(\%)$ & $7.0 \pm 1.9$ & $6.2 \pm 0.5$ & 0.160 \\
\hline $\operatorname{LVEF}(\%)$ & $56.9 \pm 9.9$ & $57.2 \pm 9.1$ & 0.948 \\
\hline $\mathrm{VO}_{2 \text { peak }}(\mathrm{mL} / \mathrm{kg} / \mathrm{min})$ & $31.5 \pm 7.4$ & $28.6 \pm 4.7$ & 0.195 \\
\hline Brachial artery diameter $(\mathrm{mm})$ & $4.04 \pm 0.34$ & $4.12 \pm 0.66$ & 0.659 \\
\hline FMD $(\%)$ & $7.36 \pm 1.48$ & $7.59 \pm 1.26$ & 0.628 \\
\hline$\Delta \mathrm{FMD}(\mathrm{mm})$ & $0.308 \pm 0.053$ & $0.318 \pm 0.066$ & 0.640 \\
\hline
\end{tabular}

Values are presented as mean \pm standard deviation.

$\mathrm{CR}$, cardiac rehabilitation; $\mathrm{BMI}$, body mass index; $\mathrm{HR}_{\mathrm{rest}}$, resting heart rate; $\mathrm{SBP}_{\text {rest }}$, resting systolic blood pressure; $\mathrm{DBP}_{\text {rest }}$, resting diastolic blood pressure; $\mathrm{HR}_{\text {peak, }}$, peak heart rate; $\mathrm{SBP}_{\text {peak }}$, peak systolic blood pressure; $\mathrm{DBP}$ peak, peak diastolic blood pressure; RER, respiratory exchange ratio; Exercise duration, maximal time to endure exercise test by modified Bruce protocol; LDL, low density lipid; HDL, high density lipid; TG, triglyceride; hs-CRP, high sensitivity C-reactive protein; HbAlc, hemoglobin Alc; LVEF, left ventricle ejection fraction; $\mathrm{VO}_{2 \text { peak }}$, peak oxygen consumption; FMD, flow-mediated dilation.

Table 3. Endothelial parameters before and after six weeks of exercise

\begin{tabular}{llccc}
\hline & & Before exercise & After exercise & p-value \\
\hline $\mathrm{VO}_{2 \text { peak }}(\mathrm{mL} / \mathrm{kg} / \mathrm{min})$ & CR group & $28.6 \pm 4.7$ & $31.1 \pm 5.1$ & $<0.001^{*}$ \\
& Control & $31.5 \pm 7.4$ & $31.4 \pm 6.0$ & 0.71 \\
$\mathrm{FMD}(\%)$ & CR group & $7.59 \pm 1.26$ & $9.46 \pm 1.82$ & $<0.001^{*}$ \\
& Control & $7.36 \pm 1.48$ & $8.31 \pm 2.04$ & 0.09 \\
\cline { 1 - 1 } $\mathrm{FMD}(\mathrm{mm})$ & CR group & $0.318 \pm 0.066$ & $0.384 \pm 0.085$ & $0.004^{*}$ \\
& Control & $0.308 \pm 0.053$ & $0.348 \pm 0.068$ & 0.05 \\
\hline
\end{tabular}

Values are presented as means \pm standard deviation.

$\mathrm{CR}$, cardiac rehabilitation; $\mathrm{VO}_{2 \text { peak }}$, peak oxygen consumption; FMD, flow-mediated dilation.

*Statistically significant at $\mathrm{p}<0.05$ within groups.

in the control. After six weeks, $\mathrm{VO}_{2 \text { peak }}$ was $31.1 \pm 5.1 \mathrm{~mL} /$ $\mathrm{kg} / \mathrm{min}$ in the CR group and $31.4 \pm 6.0 \mathrm{~mL} / \mathrm{kg} / \mathrm{min}$ in the control. The baseline $\mathrm{VO}_{\text {2peak }}$ values did not show statistically significant difference between the groups $(\mathrm{p}=0.19)$.
Comparisons between baseline and after exercise $\mathrm{VO}_{2 \text { peak }}$ values showed statistically significant improvement in the CR group $(\mathrm{p}<0.001)$, while there was no such improvement in the control $(\mathrm{p}=0.71)$ (Table 3$)$. Compar- 
ing the change of VO2 peak between the two groups, CR group showed $3.85 \pm 3.17 \mathrm{~mL} / \mathrm{kg} / \mathrm{min}$ and $-0.05 \pm 5.26 \mathrm{~mL} /$ $\mathrm{kg} / \mathrm{min}$ in control group. Both results were statistically significant $(\mathrm{p}=0.012)$.

\section{Comparison of FMD value in both groups}

The baseline FMD values were $7.59 \% \pm 1.26 \%$ in the CR group and $7.36 \% \pm 1.48 \%$ in the control. After six weeks, these were $9.46 \% \pm 1.82 \%$ in the CR group and $8.31 \% \pm 2.04 \%$ in the control. There was no statistically significant difference between the two groups ( $p>0.05$ ). Comparisons between baseline and after exercise FMD value showed statistically significant improvements in the CR group $(\mathrm{p}<0.001)$, while there no significant improvement in the control $(\mathrm{p}=0.09)$ (Table 3$)$, despite an increasing trend. Baseline FMD and the change in FMD revealed negative correlations, but it was statistically not significant $(\mathrm{r}=-0.34, \mathrm{p}=0.19)$.

\section{DISCUSSION}

In this study, CR program with six-week aerobic exercise training have shown to improve exercise capacity and endothelial function in patients with coronary artery disease, compared to the control group. It is well known that regular aerobic exercise is effective for primary and secondary prevention of cardiovascular diseases [14,15]. It has been reported that systematic CR can retard the progress or reduce the severity of atherosclerosis $[3,10,11]$ by improving cardiopulmonary function, psychosocial condition, and the quality of life, reducing all cause and cardiovascular related mortality by $20 \%-30 \%$ [15-17] and improving endothelial function.

Cornelissen et al. [18] reported that FMD test was done for patients with coronary artery disease, who had undergone a 12-week aerobic exercise to find that the aerobic exercise group showed a significant FMD increase and endothelial function improvement before and after exercise, compared to the control group. In this study, patients with coronary artery disease underwent six-week aerobic exercise. Afterwards, the FMD had significantly increased and the endothelial function had improved for the CR group, as previously reported. This study is meaningful as it shows that FMD test with less than six weeks of aerobic exercise can enhance endothelial function, while previous studies verified endothelial function im- provement with longer than twelve [18] or eight weeks of aerobic exercise [19].

As these results show, endothelial function is improved with aerobic exercise, and its main cause is known to be the stimulation of NO secretion. Physiologically, exercise temporarily produces hyperemia in the extremities and coronary artery circulation. In this way, aerobic exercise repeatedly increases the blood flow in coronary artery and peripheral blood vessels so that the shear stress in endothelial cell increases with increased NO bioavailability. According to a recently report, after an aerobic exercise, there is a correlation between the increase in FMD and the increase in endothelial nitric oxide synthase protein expression that is necessary for NO synthesis [20].

According to the study reported by Luk et al. [19], brachial artery FMD and peak MET level from GXT revealed an eight-week aerobic exercise in patients with stable coronary artery disease improved endothelial function and exercise ability. There is a negative correlation between initial brachial artery FMD and the FMD change before and after exercise. It means that effect of exercise appeared to be more significant in patients with severe endothelial function disturbance at the initial stage [19]. In our study, though not statistically significant, there was a negative correlative trend between initial brachial artery FMD and the FMD change before and after six weeks of exercise. Exercise appeared more effective for patients with severe endothelial function disturbance in the initial stage (Spearman correlation coefficient $r=-$ $0.342, \mathrm{p}=0.194)$. Since our study included 16 patients and performed six-week exercise while study of Luk et al. [19] included 32 patients for 8-week exercise, this difference might have affected the outcomes and showed statistically irrelevant results.

Even though there were no statistically meaningful changes in control group of this study, we were able to find the improving tendency of FMD after six weeks of exercise. This result has probably been influenced by the effect of statins [21] that is known to improve the endothelial function administered to most patients.

This study has several limitations. First, it was not a random comparative research, as patients themselves decided whether they would participate in the CR program. Second, the sample size was small with 16 subjects in each of the groups. Third, we have seen an improvement of endothelial function and exercise capacity by 
performing aerobic exercise in relatively short period of six weeks. But in longer period of exercise and in larger patient group study, the correlation between $\mathrm{VO}_{\text {2peak }}$ and FMD change has to be proved. Fourth, even though an experienced sonographer performed the FMD tests by manually measuring the diameter of brachial artery, there is variability in a patient and across patients due to the nature of the FMD test, which may have created bias coming from the variability of brachial diameter. Other researches have used computerized correction and wall tracking software to minimize such bias [22].

This study verifies that exercise-based CR program can improve exercise capacity and arterial endothelial function in patients with coronary artery disease.

In conclusion, CR program with six-week aerobic exercise training can improve exercise capacity and endothelial function in patients with coronary artery disease, compared to the control group. It can be verified by noninvasive FMD test and GXT. Thus, it is recommended that coronary heart disease patients participate in exercisebased CR program.

\section{CONFLICT OF INTEREST}

No potential conflict of interest relevant to this article was reported.

\section{REFERENCES}

1. Leung FP, Yung LM, Laher I, Yao X, Chen ZY, Huang Y. Exercise, vascular wall and cardiovascular diseases: an update (Part 1). Sports Med 2008;38:1009-24.

2. Vanhoutte PM, Shimokawa H, Tang EH, Feletou M. Endothelial dysfunction and vascular disease. Acta Physiol (Oxf) 2009;196:193-222.

3. Linke A, Schoene N, Gielen S, Hofer J, Erbs S, Schuler $\mathrm{G}$, et al. Endothelial dysfunction in patients with chronic heart failure: systemic effects of lower-limb exercise training. J Am Coll Cardiol 2001;37:392-7.

4. Allen JD, Cobb FR, Kraus WE, Gow AJ. Total nitrogen oxide following exercise testing reflects endothelial function and discriminates health status. Free Radic Biol Med 2006;41:740-7.

5. Verma S, Anderson TJ. Fundamentals of endothelial function for the clinical cardiologist. Circulation 2002;105:546-9.
6. Furchgott RF, Zawadzki JV. The obligatory role of endothelial cells in the relaxation of arterial smooth muscle by acetylcholine. Nature 1980;288:373-6.

7. Lüscher TF, Barton M. Biology of the endothelium. Clin Cardiol 1997;20(11 Suppl 2):II-3-10.

8. Ross R. Atherosclerosis: an inflammatory disease. N Engl J Med 1999;340:115-26.

9. Hambrecht R, Hilbrich L, Erbs S, Gielen S, Fiehn E, Schoene N, et al. Correction of endothelial dysfunction in chronic heart failure: additional effects of exercise training and oral L-arginine supplementation. J Am Coll Cardiol 2000;35:706-13.

10. Vona M, Rossi A, Capodaglio P, Rizzo S, Servi P, De Marchi $\mathrm{M}$, et al. Impact of physical training and detraining on endothelium-dependent vasodilation in patients with recent acute myocardial infarction. Am Heart J 2004;147:1039-46.

11. Farsidfar F, Kasikcioglu E, Oflaz H, Kasikioglu D, Meric M, Umman S. Effect of different intensities of acute exercise on flow-mediated dilatation in patients with coronary heart disease. Int J Cardiol 2008;124:372-4.

12. Anderson TJ, Gerhard MD, Meredith IT, Charbonneau F, Delagrange D, Creager MA, et al. Systemic nature of endothelial dysfunction in atherosclerosis. Am J Cardiol 1995;75:71B-74B.

13. Corretti MC, Anderson TJ, Benjamin EJ, Celermajer D, Charbonneau F, Creager MA, et al. Guidelines for the ultrasound assessment of endothelial-dependent flow-mediated vasodilation of the brachial artery: a report of the International Brachial Artery Reactivity Task Force. J Am Coll Cardiol 2002;39:257-65.

14. Piepoli MF, Davos C, Francis DP, Coats AJ; ExTraMATCH Collaborative. Exercise training meta-analysis of trials in patients with chronic heart failure (ExTraMATCH). BMJ 2004;328:189.

15. O'Connor GT, Buring JE, Yusuf S, Goldhaber SZ, Olmstead EM, Paffenbarger RS Jr, et al. An overview of randomized trials of rehabilitation with exercise after myocardial infarction. Circulation 1989;80:234-44.

16. Dugmore LD, Tipson RJ, Phillips MH, Flint EJ, Stentiford $\mathrm{NH}$, Bone MF, et al. Changes in cardiorespiratory fitness, psychological wellbeing, quality of life, and vocational status following a 12 month cardiac exercise rehabilitation programme. Heart 1999;81:359-66.

17. Witt BJ, Jacobsen SJ, Weston SA, Killian JM, Meverden RA, Allison TG, et al. Cardiac rehabilitation after myo- 
cardial infarction in the community. J Am Coll Cardiol 2004;44:988-96.

18. Cornelissen VA, Onkelinx S, Goetschalckx K, Thomaes T, Janssens S, Fagard R, et al. Exercise-based cardiac rehabilitation improves endothelial function assessed by flow-mediated dilation but not by pulse amplitude tonometry. Eur J Prev Cardiol 2014;21:39-48.

19. Luk TH, Dai YL, Siu CW, Yiu KH, Chan HT, Lee SW, et al. Effect of exercise training on vascular endothelial function in patients with stable coronary artery disease: a randomized controlled trial. Eur J Prev Cardiol 2012;19:830-9.

20. Hambrecht R, Adams V, Erbs S, Linke A, Krankel N,
Shu Y, et al. Regular physical activity improves endothelial function in patients with coronary artery disease by increasing phosphorylation of endothelial nitric oxide synthase. Circulation 2003;107:3152-8.

21. Beckman JA, Creager MA. The nonlipid effects of statins on endothelial function. Trends Cardiovasc Med 2006;16:156-62.

22. Walsh JH, Bilsborough W, Maiorana A, Best M, O'Driscoll GJ, Taylor RR, et al. Exercise training improves conduit vessel function in patients with coronary artery disease. J Appl Physiol (1985) 2003;95:205. 